\title{
Effects of high temperature treatments in air and argon on the magnetic properties of HITPERM alloys
}

\author{
J. S. Blázquez, ${ }^{a}$ C. F. Conde, ${ }^{a}$ A. Conde, ${ }^{a *}$ S. Roth ${ }^{b}$, A. Güth ${ }^{b}$ \\ ${ }^{a}$ Departamento de Física de la Materia Condensada. ICMSE-CSIC. Universidad de Sevilla. P.O. Box 1065. 41080 Sevilla, Spain. \\ ${ }^{b}$ IFW-Dresden, Institute for Metallic Materials, Helmholtzstrasse 20, 01069 Dresden, Germany.
}

Elsevier use only: Received date here; revised date here; accepted date here

\begin{abstract}
The oxidation behavior of the HITPERM alloy series $\mathrm{Fe}_{60} \mathrm{Co}_{18} \mathrm{Nb}_{6-\mathrm{x}} \mathrm{Zr}_{\mathrm{x}} \mathrm{B}_{16-\mathrm{z}} \mathrm{Cu}_{\mathrm{z}}(\mathrm{x}=0,3,6 ; \mathrm{z}=0$, 1) was studied. After heating up to $1073 \mathrm{~K}$, an oxide layer $\sim 1 \mu \mathrm{m}$ thick with a two-layer structure (the outer enriched in $\mathrm{Fe}$ ) can be identified previous to a sharp interface between the oxide layer and the alloy matrix, where no oxygen is detected. The alloys with $\mathrm{Zr}$ oxidize faster than the alloys without $\mathrm{Zr}$. Magnetic properties of nanocrystalline samples annealed $20 \mathrm{~h}$ at $673 \mathrm{~K}$ in air and argon show no change. However, after $50 \mathrm{~h}$ at $773 \mathrm{~K}$, the coercivity of the samples increases, the effect being more significant for the alloys without $\mathrm{Zr}$ than for those with $\mathrm{Zr}$, independently of the gas environment during the annealing. No change was observed in the microstructure after annealing and, therefore, the magnetic hardening must be due to some changes in the residual amorphous matrix.
\end{abstract}

PACS: 61.46.+w; 75.50.Tt; 81.65.Mq

Keywords: HITPERM; Nanocrystalline alloys; Oxidation; Coercivity

Soft magnetic nanocrystalline alloys, in which crystallites of about $10 \mathrm{~nm}$ are embedded in a residual amorphous matrix, have been developed as excellent candidates for soft magnetic applications [1]. This microstructure, which yields an averaging out of the magnetocrystalline anisotropy [2], is responsible for the outstanding magnetic properties observed. At the end of the last decade, new compositions $\mathrm{FeCoMBCu}$, the so-called HITPERM alloys [3], extended the applicability of nanocrystalline alloys up to higher temperatures, due to the increase of the Curie temperature of the residual amorphous phase. Although $\mathrm{Cu}$ addition is known to reduce the grain size in FINEMET and NANOPERM alloys through $\mathrm{Cu}-$ clustering [1], $\mathrm{Cu}$ clusters do not form in Zr-containing HITPERM alloys [4]. However, Cu-clustering occurs and refines the microstructure of Nb-containing HITPERM alloys [5]. To check the real possibilities for high temperature technological applications of these materials the study of the compositional effects on the nanostructure stability [6] and the oxidation behavior of HITPERM-type alloys are key questions.
In this work, the oxidation behavior in air and the effect of high temperature treatments in air and argon atmospheres on the microstructure stability of nanocrystalline $\mathrm{Fe}_{60} \mathrm{Co}_{18} \mathrm{Nb}_{6-\mathrm{x}} \mathrm{Zr}_{\mathrm{x}} \mathrm{B}_{16-\mathrm{z}} \mathrm{Cu}_{\mathrm{z}}(\mathrm{x}=0,3,6 ; \mathrm{z}=0$, 1) melt-spun ribbons $(\sim 5 \mathrm{~mm}$ wide and $\sim 15-40 \mu \mathrm{m}$ thick) were studied. In the following the compositions will be denoted as $N b 0(\mathrm{x}=0, \mathrm{z}=0), N b 1(\mathrm{x}=0, \mathrm{z}=1), N b Z r l(\mathrm{x}=3$, $\mathrm{z}=1)$ and $\operatorname{Zrl}(\mathrm{x}=6, \mathrm{z}=1)$. The oxidation process was studied using a thermobalance (TG) Perkin-Elmer TGA7, in order to obtain the in-situ mass gain of the samples during the heat treatments. Scanning electron microscopy (SEM) 


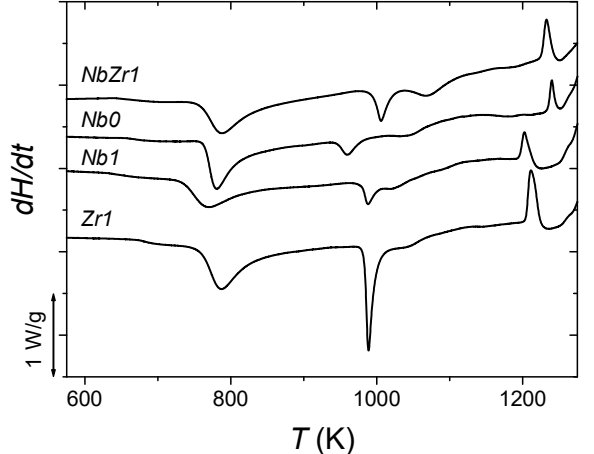

Fig. 1. DSC scans at $20 \mathrm{~K} / \mathrm{min}$ of the as-cast studied alloys.

images from back scattered electrons (BSE) and secondary electrons (SE) were used to study the formed oxide layer and its composition was obtained by energy dispersive Xray spectroscopy (EDX). A Netzsch DSC 404 differential scanning calorimeter (DSC) was used to study the devitrification process (in argon atmosphere) and the long time annealing of samples in air and argon atmospheres. The microstructure (lattice parameter, $a$, grain size, $D$, and crystalline volume fraction, $X$ ) was studied using a Philips PW 1050 diffractometer with Co K $\alpha$ radiation. Coercivity, $H_{C}$, was measured using a Förster Koerzimat. Figure 1 shows DSC scans at $20 \mathrm{~K} / \mathrm{min}$ for as-cast samples of the four studied alloys. Two main exothermic peaks are detected: the first one $(\sim 750 \mathrm{~K})$ corresponds to the formation of $\alpha$-Fe type nanocrystals and the second one $(\sim 1000 \mathrm{~K})$ to the formation of boride phases [7]. The endotherm observed above $1200 \mathrm{~K}$ corresponds to the $\alpha-\gamma$ transition of Fe.

Figure 2 shows the mass gain of the as-cast alloys as a function of the temperature. Below $850 \mathrm{~K}$ there is no significant mass change but at this temperature an increase occurs (faster for $\mathrm{Zr}$-containing alloys), which saturates at about $0.05 \mathrm{mg} / \mathrm{cm}^{2}$ of mass gain. Above $975 \mathrm{~K}$ a new mass increase is observed, which does not saturate in the temperature range of our experiment. After this treatment (heating in air up to $1073 \mathrm{~K}$ ) the microstructure of the samples was studied by XRD, SEM and EDX. In agreement with DSC results, XRD shows that samples are fully crystallized and, besides $\alpha$-Fe and borides, $\mathrm{Fe}_{3} \mathrm{O}_{4}$ and $\mathrm{Fe}_{2} \mathrm{O}_{3}$ lines appear. SEM pictures (an example is shown in Fig. 3 for $\mathrm{NbZrl}$ alloy) show a clear interface between the alloy matrix (without contrast by SE) and the oxide layer (showing porosity by SE). The oxide layer is $\sim 1 \mu \mathrm{m}$ thick and shows a two-layer structure (clearly observed by BSE). The outer oxide layer is richer in $\mathrm{O}$ and $\mathrm{Fe}$ and the inner one is enriched in $\mathrm{Co}, \mathrm{Zr}$ and/or $\mathrm{Nb}$. The alloy matrix is oxygen free and the ratio between $\mathrm{Fe}, \mathrm{Co}, \mathrm{Zr}$ and $\mathrm{Nb}$ is that of the nominal composition. B content can not be measured with this technique.

Nanocrystalline samples $(X \sim 70-80 \%$, and $D \sim 8-15 \mathrm{~nm})$ of the different alloys were obtained after annealing the

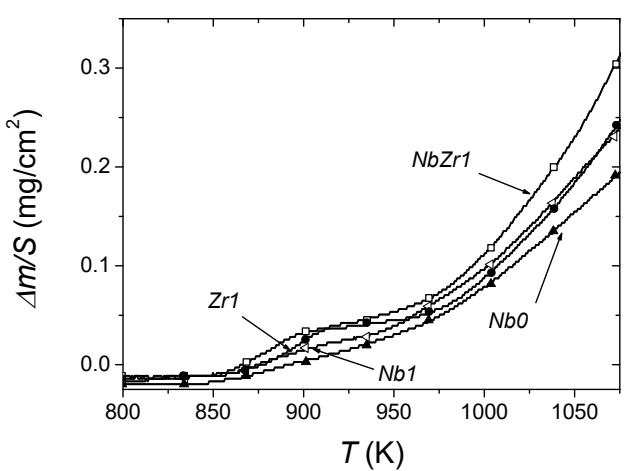

Fig.2. Specific mass gain obtained at $40 \mathrm{~K} / \mathrm{min}$ by $\mathrm{TG}$ for the studied alloys

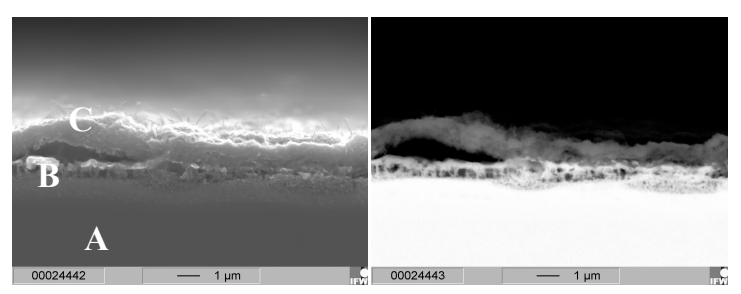

Fig. 3. SEM images showing the structure of the oxide layer of NbZrl alloy heated up to $1073 \mathrm{~K}$. Left, SE image; right, BSE image. The labels A, B, C correspond to the alloy matrix, the inner oxide layer and the outer oxide layer, respectively.

corresponding amorphous precursor alloys during $5 \mathrm{~min}$ at $873 \mathrm{~K}$ in argon. Then, they were submitted to an additional long time annealing in air or argon atmosphere in order to study the compositional dependence of the oxidation and the thermal stability of the microstructure as well as their effects on the magnetic properties. TG results on samples annealed $50 \mathrm{~h}$ at $773 \mathrm{~K}$ show a mass gain lower than $0.05 \mathrm{mg} / \mathrm{cm}^{2}$ for the alloys with $\mathrm{Zr}$ (which would correspond to an oxide layer $\sim 100 \mathrm{~nm}$ thick) and a negligible increase for the $\mathrm{Zr}$-free alloys $\left(<0.015 \mathrm{mg} / \mathrm{cm}^{2}\right)$. The long time annealing do not apparently modify the microstructure of the nanocrystalline samples observed by XRD (see table I) and $a$ and $D$ values remain constant.

No appreciable change can be observed for the magnetic properties of nanocrystalline samples after annealing $20 \mathrm{~h}$ at $673 \mathrm{~K}$ in air or argon with respect to the non-additionally annealed nanocrystalline samples. However, annealing for $50 \mathrm{~h}$ at $773 \mathrm{~K}$ in air yields a clear magnetic hardening for all the studied compositions, being higher for the $\mathrm{Zr}$-free alloys, which is opposite to the expected effect if the formation of oxides were the responsible for this magnetic hardening. In order to understand this fact, the annealing was repeated in argon for $\mathrm{Nbl}$ and $\mathrm{Zrl}$ alloys and no significant change was observed with respect to the airannealed samples (see table II). Consequently, this hardening can not be due to the oxide formation. On the other hand, the nanocrystals show no changes after the 
annealing (nor compositional, through a change of $a$, neither grain coarsening) and there are no traces of boride phases in the XRD patterns. Therefore, the magnetic hardening of the alloys observed after $50 \mathrm{~h}$ at $773 \mathrm{~K}$ must be due to some change in the residual amorphous matrix, implying different environments for $\mathrm{Nb}$ and $\mathrm{Zr}$ atoms, which could be associated to the different crystalline phases formed during the second crystallization stage. In fact, $\mathrm{Zr}$-free alloys show a clear increase in $M_{S}$ after annealing at $773 \mathrm{~K}$ in air with respect to non-additionally annealed nanocrystalline samples. However, the increase observed after annealing $773 \mathrm{~K}$ in argon is at the limit of the error bar (see table I). Heat treatments in air or hydrogen could yield a migration of $\mathrm{B}$ to the surface where it is removed from the alloy as oxide or hydride [8, 9], which would modify the amorphous composition and would even facilitate an increase of the $\alpha$-Fe phase. This phenomenon seems to be less effective in $\mathrm{Zr}$ containing alloys.

In conclusion, nor oxidation neither grain coarsening are relevant to describe the magnetic hardening observed in nanocrystalline HITPERM-type studied alloys after long time annealing at $773 \mathrm{~K}$. This coercivity increase, higher in the alloys without $\mathrm{Zr}$, might be associated to changes in the residual amorphous matrix involving the $\mathrm{Zr}$ or $\mathrm{Nb}$ atomic enviroments.

Table I. Microstructure and magnetic properties of nanocrystalline alloys without additional annealing treatment (Nano) and after two additional long time annealing: $20 \mathrm{~h}$ at $673 \mathrm{~K}$ and $50 \mathrm{~h}$ at $773 \mathrm{~K}$.

\begin{tabular}{|c|c|c|c|c|c|}
\hline \multirow[t]{2}{*}{ alloy } & \multirow{2}{*}{$\begin{array}{l}\text { Nano } \\
5 \mathrm{~min} \\
873 \mathrm{~K}\end{array}$} & \multicolumn{2}{|c|}{$\begin{array}{c}+20 \mathrm{~h} \\
673 \mathrm{~K}\end{array}$} & \multicolumn{2}{|c|}{$\begin{array}{l}+50 \mathrm{~h} \\
773 \mathrm{~K}\end{array}$} \\
\hline & & Argon & Air & Argon & Air \\
\hline \multicolumn{6}{|c|}{ Nanocrystal grain size $(D \pm 2) \mathrm{nm}$} \\
\hline $\mathrm{Nbl}$ & 8 & 8 & 8 & 9 & 9 \\
\hline $\mathrm{NbO}$ & 15 & 15 & 15 & & 15 \\
\hline$N b Z r 1$ & 8 & 8 & 8 & & 8 \\
\hline$Z r 1$ & 9 & 8 & 8 & 15 & 12 \\
\hline \multicolumn{6}{|c|}{ Lattice parameter of $\alpha-\mathrm{Fe}, \mathrm{Co}(a \pm 0.005) 10^{-10} \mathrm{~m}$} \\
\hline $\mathrm{Nbl}$ & 2.867 & 2.865 & 2.866 & 2.864 & 2.863 \\
\hline $\mathrm{NbO}$ & 2.871 & 2.868 & 2.868 & & 2.868 \\
\hline $\mathrm{NbZr1}$ & 2.869 & 2.868 & 2.863 & & 2.865 \\
\hline$Z r 1$ & 2.870 & 2.869 & 2.869 & 2.869 & 2.869 \\
\hline \multicolumn{6}{|c|}{ Coercivity $\left(H_{C} \pm 5 \mathrm{~A} / \mathrm{m}\right)$} \\
\hline $\mathrm{Nbl}$ & 26 & 32 & 33 & 133 & 137 \\
\hline $\mathrm{NbO}$ & 43 & 57 & 55 & & 222 \\
\hline$N b Z r 1$ & 22 & 26 & 28 & & 89 \\
\hline$Z r 1$ & 29 & 26 & 29 & 96 & 83 \\
\hline \multicolumn{6}{|c|}{ Saturation Magnetization $\left(M_{S} \pm 5 \mathrm{emu} / \mathrm{g}\right)$} \\
\hline $\mathrm{Nbl}$ & 165 & 161 & 164 & 177 & 196 \\
\hline $\mathrm{NbO}$ & 180 & 176 & 179 & & 205 \\
\hline NbZrl & 165 & 161 & 163 & & 163 \\
\hline$Z r 1$ & 174 & 176 & 167 & 165 & 174 \\
\hline
\end{tabular}

\section{Acknowledgements}

This work was supported by the Spanish Government and EU FEDER (Project MAT 2004-04618). J.S. Blázquez acknowledges a research contract from the Regional Government of Andalucía (Spain).

\section{References}

[1] M.E. McHenry, M.A. Willard, D.E. Laughlin, Progress in Mater. Sci. 44 (1999) 291.

[2] A. Hernando, M. Vázquez, T. Kulik, C. Prados, Phys. Rev. B 51 (1995) 3581.

[3] M.A. Willard, D.E. Laughlin, M.E. McHenry, D. Thoma, K. Sickafus, J. O. Cross, V. G. Harris, J. Appl. Phys. 84 (1998) 6773

[4] D.H. Ping, Y.Q. Wu, K. Hono, M.A. Willard, M.E. McHenry, D.E. Laughlin, Scripta Mater. 45 (2001) 781

[5] Y. Zhang, J.S. Blázquez, A. Conde, P.J. Warren, A. Cerezo, Mat. Sci. Eng. A 353 (2003) 158.

[6] J. Ferenc, J. Latuch, T. Kulik, J. Magn. Magn. Mater. 272-276 (2004) 1469.

[7] J. S. Blázquez, C. F. Conde, A. Conde, J. Non-Cryst. Solids 287 (2001) 187

[8] G. Wei, B. Cantor, Acta Met. 36 (1988) 2293.

[9] G. Saage, S. Roth, J. Eckert, L. Schultz, Mat. Sci. Eng. A 375377 (2004), 1125 